\title{
Tympanolith under the Protiniculum - A Case Report
}

\author{
Aditya Yeolekar ${ }^{1 *}$, Pooja Sancheti², Kiran J Shinde ${ }^{3}$ \\ ${ }^{1}$ Associate Professor, Department of ENT \& HNS, Smt. Kashibai Navale Medical College, India \\ ${ }^{2}$ Senior Resident, Department of ENT \& HNS, Smt. Kashibai Navale Medical College, India
}

${ }^{3}$ Prof and Head, Department of ENT \& HNS, Smt. Kashibai Navale Medical College, India

*Corresponding author: Aditya Yeolekar, Associate Professor, Department of ENT \& HNS, Smt. Kashibai Navale Medical College, India

\begin{abstract}
Background: A tympanolith is a calcified body found impacted in mucosa of the middle ear. It is thought to be intrinsic deposition of calcium over a nidus of mucous plug whereas a foreign body is usually extrinsic.

Case Report: A young male with bilateral ear inactive chronic mucosal type of otitis media was posted for tympanoplasty. A full cuff incision and exploration of ear showed a smooth gritty hard stone stuck in the hypotympanum later confirmed to be a tympanolith. Middle ear anatomy of hypotympanum was studied with straight and angled endoscope. A type A configuration of bony crest of Protiniculum was found to be the reason for formation of mucus plug and lith.

Discussion: Tympanolith is a rare condition which is known to occur in a chronically discharging ear, due to calcium deposition on a mucus plug or biofilm formation. Tympanolith is a bony crest in hypotympanum with variable anatomy.

Conclusion: Every nook and corner of the middle ear should be inspected while doing a tympanoplasty to rule out tympanolith, foreign body or granulations. Either a full cuff incision microscopic tympanoplasty or an inspection of middle ear by angled endoscope in every case are suggested options.
\end{abstract}

Keywords: Tympanolith;protiniculum;protympnanum

\section{Introduction}

Foreign body in the external auditory canal is common and often treated in an outpatient basis. The foreign bodies commonly found in the external auditory canal include animate and inanimate objects like stones, insects, erasers, buttons, vegetable pieces, cereals and pulses, cotton ball, bits of metal from welding, most common being beads, paper/tissue paper or popcorn kernels[1,2]. A tympanolith (stone in the middle ear) is a calcified body in the tympanic cavity, which can be extrinsic (foreign body) or intrinsic ( purulent dried discharge or stagnant mucus acting as a nidus for calcification) [3]. Anything small enough to pass the isthmus of the external auditory canal and missed may cause a perforation of the tympanic membrane, to ultimately find its way into the middle ear. Also,an extrinsic foreign body can travel through the perforated ear drum and get impacted in the mucosa of the middle ear. A tympanolith is a rare condition and there are very few cases reported in literature. Gapany-gapanavicius et al. publication is one of those few cases reported[4]. Long standing ear diseases may harbor a tympanolith. Small ones may be asymptomatic and accidentally diagnosed during examination and surgery of the ear. Larger ones usually present with symptoms like ear discharge, earache, aural fullness, decreased hearing.Protiniculum has been described as a bony ridge extending from the promontory towards the protympanum on the medial wall of the middle ear cavity, across the inferior wall and merging with the lateral wall. The medial aspect of the ridge is marked by the end of the most anterior hypotympanic air cell and start of the pro tympanum, consistently[5]. This lies inferior to the ET tube opening. 


\section{Case Report}

A 24-year-old male, salesman by profession came with complaints of bilateral intermittent ear discharge since three years to the outpatient department of a rural tertiary care hospital in western India . The discharge was mucopurulent, non-foul smelling and non-blood stained. There was history of similar episodes of ear discharge in childhood. A diagnosis of bilateral mucosal chronic otitis media was made.The patient also emphasized on difficulty in hearing which had become more evident in the last three years, more in right ear. There was no history of trauma or foreign body insertion in the ear. After achieving the inactive stage of the disease with topical and systemic medications, the pure tone audiometry was done, and it showed bilateral mild conductive hearing loss. The right large central perforation with left medium sized central perforation was confirmed with examination under microscope.

The patient was prepared and posted for right tympanoplasty under general anaesthesia.With a post aural approach and full cuff tympan meatal flap elevation, the ossicular continuity was checked. The temporalis fascia graft was planned to be placed by underlay technique to achieve a type I tympanoplasty. During flap elevation on the anterior wall of the external auditory canal, a shiny blackish brown about $4 \mathrm{~mm}$ sized structure was noticed just below the eustachian tube opening. It was initially thought to be a clot. It was palpated with a probe and found to be hard in consistency. The zerodegree endoscope was introduced to confirm this. The structure did not loosen up on suctioning and tactful manipulation was done with a ball probe and suction to dislocate it from the mucosal bed and removed. The graft was placed as planned. It was $4 \mathrm{~mm}$ in size, oblong, gritty and hard, surface was irregular, blackish brown, and was sent for further analysis. The chemical analysis confirmed it to be a calcium containing lith. Post operatively patient received antibiotics and the graft was successfully taken up.

\section{Discussion}

A tympanolith is a calcified body in the tympanic cavity, known to occur from long standing chronic suppurative otitis media with central perforation, like a rhinolith in the paranasal sinuses. The frequent ear discharge and stagnant mucus in the middle ear acts as a nucleus for the calcium salt deposition[3].The protympanum is a middle ear space anterior to the mesotympanum, confluent with the epitympanum superiorly and hypo tympanum inferiorly. It has been infrequently examined in the past due to difficulty in visualization with a microscope. The area is now gaining relevance with more frequent uses of endoscopes during middle ear surgeries. The protympanum serves as the final common pathway between the tympanic cavity and the external environment. Its boundaries being more defined now with use of straight and angled endoscopes. Inferior boundary of the protympanum is marked by an oblique bony ridge called protiniculum, posteriorly, extending anteriorly with the presence of protympanic air cells, which is an anterior extension of hypotympanic air cells[5]. The protympanic crest was described by Abou-Bieh and colleagues in 79 percent of temporal bones studied radiologically and directly[6]. This bony ridge has been named the protiniculum from the latin word "protinus "which means forward or farther on [7]. This nomenclature is similar to the other promontorial bony ridges. It has three conformations:

a) Type A:Ridge, with no air cells medial to it.

b) Type B: Bridge, hypotympanic air cells extending into the protympanum.

c) Type C: Absent, no discernible protiniculum, the hypotympanum fused with protympanum(Figure 1) [5].

Our patient seemed to have a type A protiniculum and the foreign body was located just inferior to the ridge (Figure 2). There is a possibility of the inspissated stagnant mucus which may have not drained into the protympanum due to the ridge superiorly and acted as a nidus for calcium salts to deposit(Figure 3).The protympanic area has pseudo stratified ciliated columnar epithelium with mucus secreting cells like the nasal mucosa. The physiological function is predominantly mucociliary clearance towards the eustachian tube[8]. When inflamed, protympanic epithelium thickens and becomes polypoidal. The ciliated cells decrease, residual cilia collapse and leads to stagnation of mucus secretion.Mucosal cells contain numerous secretory granules. Polymorphonuclear cells are present submucosally and bacteria on the mucosal surface[9]. The biofilm formation is more likely to be present in the pro tympanum in cases of chronic suppurative otitis media[10,11].

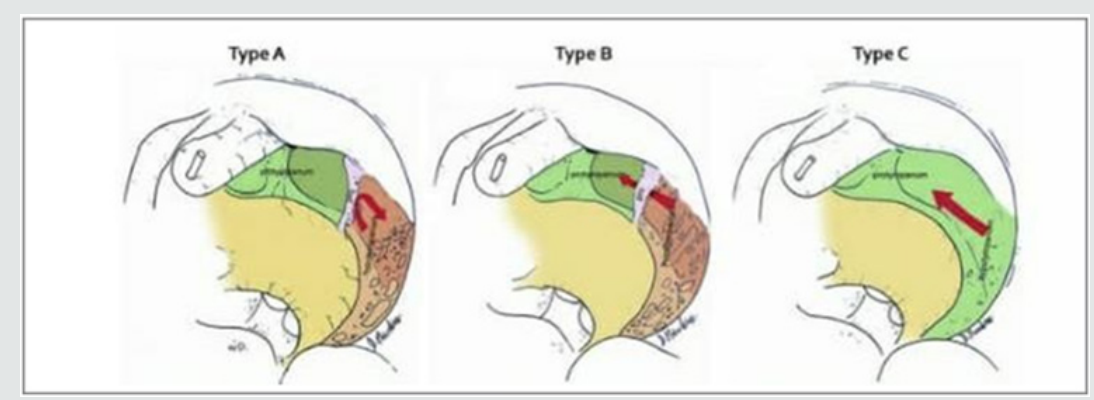

Figure 1: Protiniculum in the hypotympanum[5]. 


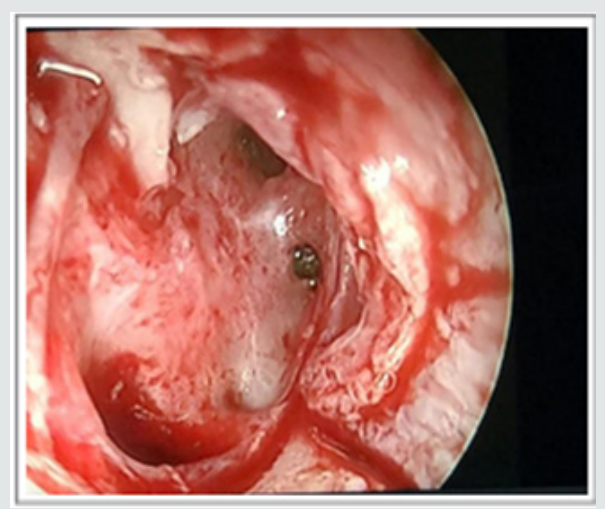

Figure 2: Endoscopic view of middle ear showing tympanolith below the bony crest (protiniculum) in the hypotympanum.

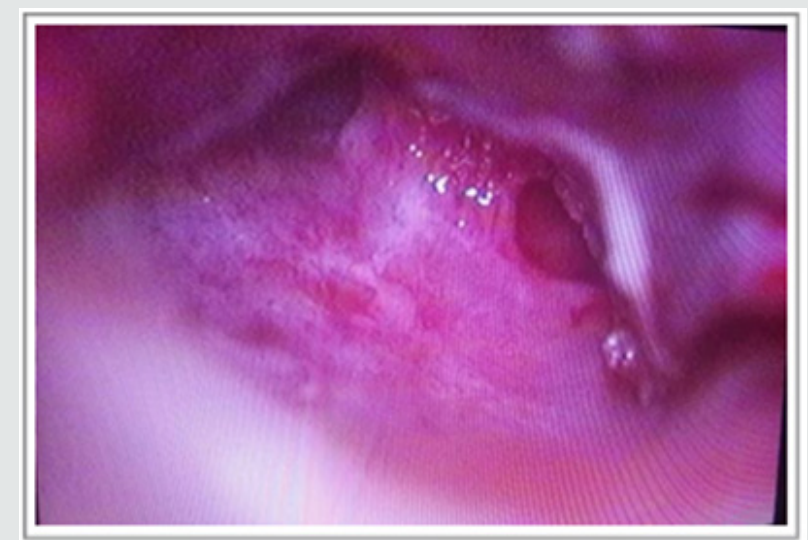

Figure 3: Microscopic view of middle ear after removal of tympanolith.

\section{Conclusion}

The protympanum and protiniculum are very important areas and the final common pathway of ventilation of middle ear and mastoid system. The use of angled (30 and 45 degree) and straight ( 0 degree) endoscopes allows easy access and complete examination of these areas, including removal of polyp, granulation or as in this case, foreign bodies. The use of endoscopes as an adjunct to microscope in ear surgeries seems essential now. And with complete understanding of the middle ear endoscopic anatomy and ventilation pathways we can achieve a more physiological goal during surgeries. An incidental tympanolith in our patient reemphasizes the importance of the habit of inspecting middle ear, every nook and cranny if possible, during every tympanoplasty with a straight or angled endoscope.

Conflicts of Interests:The authors declare that they have no conflicts of interests

Acknowledgements: Dr Nirmal Patel, Australia for permission to share illustration (Figure 1).

\section{References}

1. Schulze SL, Kerschner J, Beste D (2002) Pediatric external auditory canal foreign bodies: a review of 698 cases. Otolaryngol Head Neck Surg 127(1): 73-78.

2. FalconChevere JL, Giraldez L, RiveraRivera JO, Suero Salvador T (2013) Critical ENT skills and procedures in the emergency department. Emerg. Med Clin North Am 31(1): 29-58.

3. A Nagalingeswaran, RD Kumar (2018) Tympanolith in the Middle Ear. Annals of Otology and Neurootology 1(2): 123-125.

4. Gapany Gapanavicius B, Sela J, Levij IS (1977) Chronictympanomastoiditis with formation of calculi. Ann Otol Rhinol Laryngol 86 (3 Pt 1): 386-391.

5. Jufas N, Marchioni D, Tarabichi M, Patel N (2016) Endoscopic anatomy of the protympanum. Otolaryngol Clin North Am 49(5): 1107-1119.

6. Abou Bieh AA, Al Abdulhadi K, Al Tubaikh J (2009) The protympanic crest. Otolaryngol Head Neck Surg 141(3): 92.

7. Marchioni D, Alicandri Ciufelli M, Piccinini A (2010) Inferior retrotympanum revisited: an endoscopic anatomic study. Laryngoscope 120(9): 1880-1886.

8. Ars B, Ars Piret NM (2007) Morphofunctional partition of the middle ear cleft. Mediterr J Otol 3: 31-39.

9. Chao WY, Chang SJ (1996) Ultrastructure of eustachian tube mucosa in chronic otitis media with cholesteatoma. Am J Otolaryngol 17(3): 161166.

10. Saafan ME, Ibrahim WS, Tomoum MO (2013) Role of adenoid biofilm in chronic otitis media with effusion in children. Eur Arch Otorhinolaryngol 270(9): 2417-2425.

11. Homøe P, Bjarnsholt T, Wessman M (2009) Morphological evidence of biofilm formation in Greenlanders with chronic suppurative otitis media. Eur Arch Otorhinolaryngol 266(10): 1533-1538. (c) (P) This work is licensed under Creative

To Submit Your Article Click Here:

Submit Article
DOI: $10.32474 /$ SJ0.2020.05.000201

Citation: Aditya Yeolekar, Pooja Sancheti, Kiran J Shinde. Tympanolith under the Protiniculum - A Case Report. Sch J Oto 5(1)-2020. SJ0. MS.ID.000201. DOI: 10.32474/SJ0.2020.05.000201.

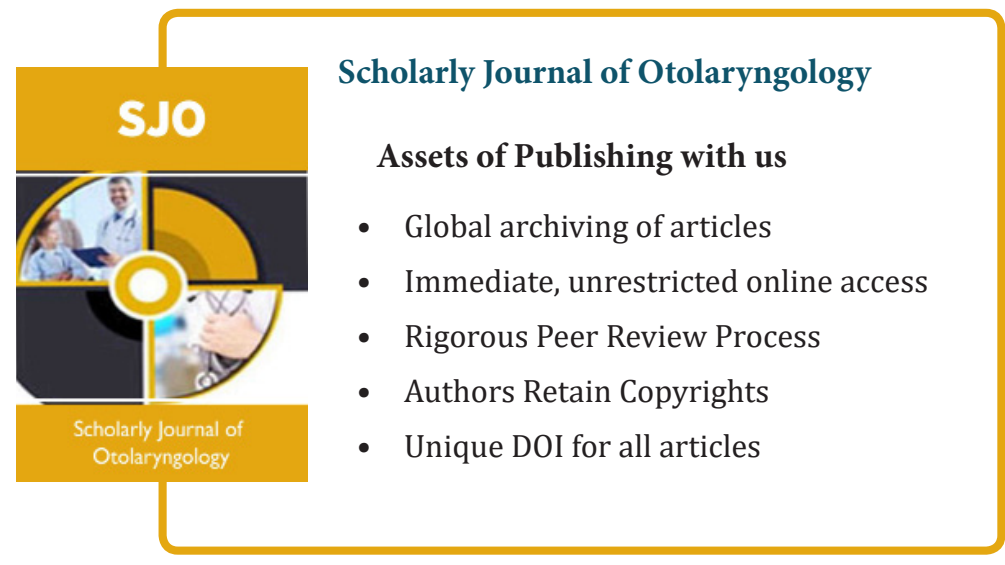

